\title{
Seasonal and monthly variation in occurrence of hypertensive urgency
}

\author{
Sadip Pant · Apurva O. Badheka $\cdot$ Kathan Mehta $\cdot$ \\ Abhishek Deshmukh
}

Received: 16 December 2012/ Accepted: 23 January 2013/Published online: 6 February 2013

(c) SIMI 2013

Dear Editor,

We read with a great interest the article published by Marchesi et al. [1] in the journal "Internal and Emergency Medicine" entitled "Seasonal and monthly variation in occurrence of hypertensive urgency". The authors have demonstrated from a hospital-based study of 360 subjects in Italy that the peak number of hypertensive urgency episodes occurred in December and the nadir in May. We have recently published an analysis of 456,259 hypertensive emergency hospitalizations from 2000 to 2007 in the United States where a similar pattern with winter peak and summer trough was noted [2]. The mean number of hospitalizations each day (averaged over the 8 years study frame) was least in June and maximum in February. Although, a seasonal fluctuation in blood pressure has been known for decades [3, 4], their translation into hospitalizations is reflected for the first time in our study. Winter peak in hypertensive urgency/emergency could also be a trigger for stroke and acute myocardial infarction. Over the last decade, the number of hospitalizations for hypertensive

\section{S. Pant $(\bowtie)$}

Department of Internal Medicine,

University of Arkansas for Medical Sciences,

Little Rock, USA

e-mail: sadippant@hotmail.com

\section{A. O. Badheka}

Department of Cardiology, University of Miami-Miller

School of Medicine, Miami, USA

K. Mehta

Department of Biostatistics, Drexel School of Public

Health-Drexel University, Philadelphia, USA

A. Deshmukh

Department of Cardiology, University of Arkansas

for Medical Sciences, Little Rock, USA emergency has consistently increased [5]. The authors have correctly pointed out that such seasonal fluctuations are interesting to know as closer follow-up of the blood pressure during winter months may help prevent hypertensive crisis related hospitalizations and the health care costs associated with this.

Conflict of interest None.

\section{References}

1. Marchesi C, Dentali F, Maresca AM, Gessi V, Manfredini R, Grandi AM (2012) Seasonal and monthly variation in occurrence of hypertensive urgency. Intern Emerg Med Nov 29 [Epub ahead of print]

2. Deshmukh A, Pant S, Kumar G, Murugiah K, Mehta J (2012) Seasonal variation in hypertensive emergency hospitalization. J Clin Hypertens (Greenwich) 14:269-270

3. Brown GE (1930) Daily and monthly rhythm in blood pressure of man with hypertension. Ann Intern Med 3:1177-1189

4. Rose G (1961) Seasonal variation in blood pressure in man. Nature 189:235

5. Deshmukh A, Kumar G, Kumar N, Nanchal R, Gobal F, Sakhuja A, Mehta JL (2011) Effect of Joint National Committee VII report on hospitalizations for hypertensive emergencies in the United States. Am J Cardiol 108:1277-1282 